\title{
Profile of Traumatic Hip Dislocations in a West African Teaching Hospital
}

\author{
Patrick W. H. Dakouré1, Malick Diallo', Thierry A. W. Guigma', Massadiami Soulama1, \\ Salifou Gandéma²
}

${ }^{1}$ Service d'Orthopédie Traumatologie, CHU Sourô Sanou, Bobo-Dioulasso, Burkina Faso

${ }^{2}$ Service de Rééducation Fonctionnelle, CHU Sourô Sanou, Bobo-Dioulasso, Burkina Faso

Email: patdakoure@gmail.com

How to cite this paper: Dakouré, P.W.H. Diallo, M., Guigma, T.A.W., Soulama, M. and Gandéma, S. (2017) Profile of Traumatic Hip Dislocations in a West African Teaching Hospital. Open Journal of Orthopedics, 7, 345-355.

https://doi.org/10.4236/ojo.2017.711035

Received: October 4, 2017

Accepted: November 6, 2017

Published: November 9, 2017

Copyright (C) 2017 by authors and Scientific Research Publishing Inc. This work is licensed under the Creative Commons Attribution International License (CC BY 4.0).

http://creativecommons.org/licenses/by/4.0/

\begin{abstract}
Purpose: Traumatic hip dislocations (THD) are rarely reported from developing countries. The aim of the current study is to describe the trauma, the presentation, the treatment and the outcome patterns of THD received in the trauma unit of an emergency department (ED) in west Africa. Patients and Methods: A retrospective ongoing study from 2008 to 2014 was performed at the ED. All patients over 15 years with an unreduced THD and an anteroposterior pelvic radiograph were studied. Data were collected and analyzed by means of a statistical software. Results: A total of 50 THD were included in the study. We found an average of seven dislocations per year with a mean age of 36 years mainly males $(n=37)$. Road traffic accidents by motorcycle $(n=$ 20) were the common circumstance of trauma. Forty-five extra-pelvic THD were diagnosed. According to the Bigelow classification, THD were classified posterior $(\mathrm{n}=33)$, anterior $(\mathrm{n}=10)$ and irregular $(\mathrm{n}=2)$. Associated acetabular fractures $(n=36)$, ipsilateral lower limb fractures $(n=10)$ and sciatic nerve palsy $(\mathrm{n}=2)$ were also found. The THD cases were treated by closed reduction $(n=34)$, open reduction $(n=6)$ and Girdlestone procedure $(n=1)$. The outcome after 16 months showed 21 good and excellent functional results and one death. The short term complications were post traumatic arthritis $(\mathrm{n}=10)$ and osteonecrosis $(\mathrm{n}=2)$. Conclusion: The THD occurrences are important in our emergency department. They are characterized by the place of motorcycle accidents and by the delayed reduction due to hospital's locations and numbers and beliefs. A reduction before four hours, an earlier rehabilitation, a non-use of traction and a short hospitalization time below 14 days gave better results.
\end{abstract}

\section{Keywords}

Developing Country, Dislocation, Hip, Motorcycle, Traumatic 


\section{Introduction}

The traumatic hip dislocations (THD) are rare occurrence [1]. Large series of THD require long-term studies, multicenter studies and, disasters [2] [3] [4] [5] [6]. Their prognosis is linked to associated peri-articular fractures and an early reduction within the six hours [2] [3] [4] [5] [6]. Well-described in international literature since Bigelow [7], the THD patterns are rarely studied in developing countries [8] [9].

The aim of our study is to describe socio-demographic, etiologic, anatomopathologic, the therapeutic features, and the outcome features of the THD received in a trauma center of a West African country.

\section{Material and Methods}

\subsection{Settings}

Our hospital is the second university teaching hospital of the country. The Orthopedic and Trauma department was created in 2008. The hospital is the only facility offering twenty-four hour specialized trauma care and rehabilitation for the patients from the western part of the country (around five billions inhabitants) and the surrounding countries. In 2015, the Department had four senior orthopedic surgeons, four junior surgeons, six wards, 30 beds and, one operating room.

\subsection{Study Design}

A retrospective study spanning 81 months from January 2008 to September 2014 was carried in our trauma emergency department (ED). All cases of unreduced THD in adults over 15 years old were included in the study. The socio-demographic features, the circumstances of trauma, the mechanisms of injury, the clinical findings, the treatment and the follow-up variables were identified (Table 1). These variables were collected by means of medical files records, and by phone. The pelvic anteroposterior radiographs before and after reduction were performed in all cases. The functional outcome was evaluated according to the Harris Hip Score (HHS) [10]. The THD cases with incomplete medical files records were excluded. Variables were encoded and analyzed by the statistical software STATA version 12 (StataCorp ${ }^{\circledR}$, Texas, USA). The Pearson test was used for correlations (r) with a significant level of $5 \%$.

\section{Results}

Fifty-two cases of THD were found among 17,192 surgical emergency patients. Two cases with incomplete medical records were removed from the sample.

\subsection{Socio-Demographic Features}

The number of THD cases had increased from 2008 to 2014 with an average of seven cases per year $(6.51-7.57$ CI 95\%). The majority of cases $(n=27)$ came from 100 to $200 \mathrm{~km}$. The mean age was 36 years old (32.00 - 40.03). Thirty-two 
Table 1. Studied variables.

\begin{tabular}{|c|}
\hline Socio-demographic features \\
\hline Age \\
\hline Sex \\
\hline Occupation \\
\hline Provenance \\
\hline Trauma features \\
\hline Trauma circumstances \\
\hline Mechanisms of injury \\
\hline Clinical features \\
\hline Time of admission \\
\hline Dislocation type \\
\hline Associated complications \\
\hline Treatment features \\
\hline Time of reduction \\
\hline Reduction method \\
\hline Associated treatments \\
\hline Hospitalization time \\
\hline Follow-up features \\
\hline Follow-up time \\
\hline Functional outcome (the Harris Hip Score) \\
\hline Late complications \\
\hline
\end{tabular}

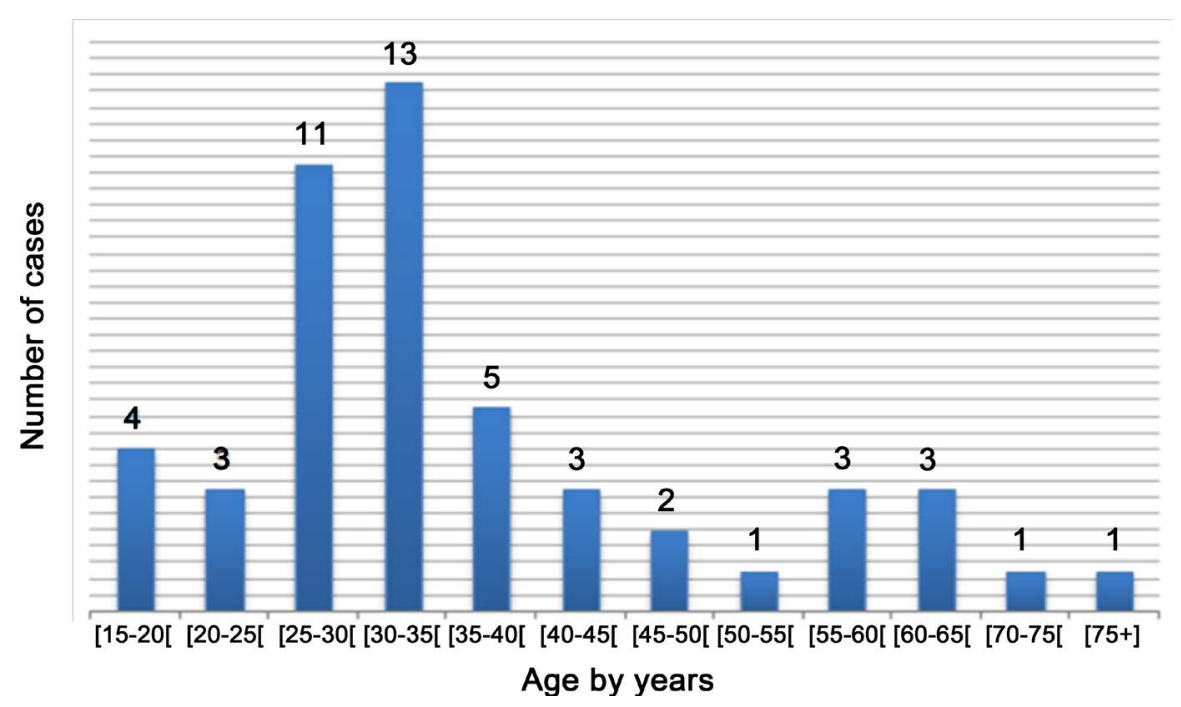

Figure 1. THD cases distribution by age.

cases were aged between twenty and forty years old (Figure 1).

The male: female ratio was 2.85. Mean ages at the trauma time was 37 years for men and 32 years for women. Sixty percent of injured patients are farmers and informal sector workers (Figure 2). 


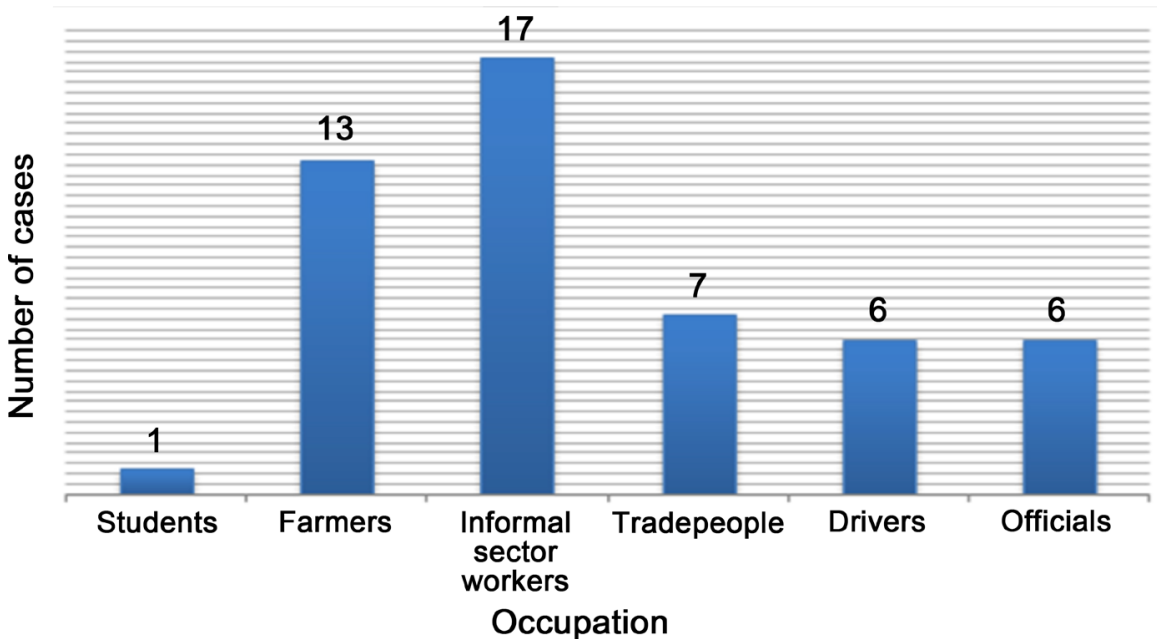

Figure 2. THD cases distribution by occupation.

Table 2. Trauma circumstances and mechanisms.

\begin{tabular}{ccc}
\hline Trauma circumstances & Mechanisms of injury & Cases (n) \\
\hline Aggressions/Violences & Fall from height & 1 \\
Everyday accidents & Fall from height & 2 \\
Work accident & Fall from height & 1 \\
Road Traffic accident & Hit & 45 \\
Railway Traffic accident & Hit & 1 \\
\hline
\end{tabular}

\subsection{Circumstances and Mechanisms of Injury (MOI)}

Five patients had an associated condition to their THD such as a pregnancy $(\mathrm{n}=$ $1)$, a hip osteoarthritis $(n=1)$, a chronic epiphysiolysis $(n=1)$, a peri-articular calcification $(n=1)$ and an osteoporosis $(n=1)$. The main circumstance of trauma was road traffic accident $(n=45)$ (Table 2).

A collision with an environmental object was commonly found in motorcycle accidents $(\mathrm{n}=22)$ (Figure 3). Falls from height were less frequent $(\mathrm{n}=4)$ and diversified (tree, balcony, scaffolding).

\subsection{Clinical Findings}

We used Pelvic AP and oblique views to describe the dislocations forms and the associated bony lesions. Fifteen cases of THD occurred in polytrauma patients. It was 25 right injured hips and 25 left injured hips. We found five intra-pelvic dislocations with acetabular fractures and 45 extra-pelvic dislocations. Extrapelvic dislocations were classified according to the Bigelow Classification 7 to irregular type $(n=2)$ (Figure 4$)$ and regular type $(n=43)$.

Three fourth of Three fourth of regular dislocations were posterior (Table 3 , Figure 5).

An associated periarticular fracture was frequent $(n=48)$, mainly an acetabular fracture $(\mathrm{n}=36)$ (Figure 6$)$ and other associated fractures were commonly located on the ipsilateral pelvic limb (femur, tibia, pelvis, etc.) (Table 4). 


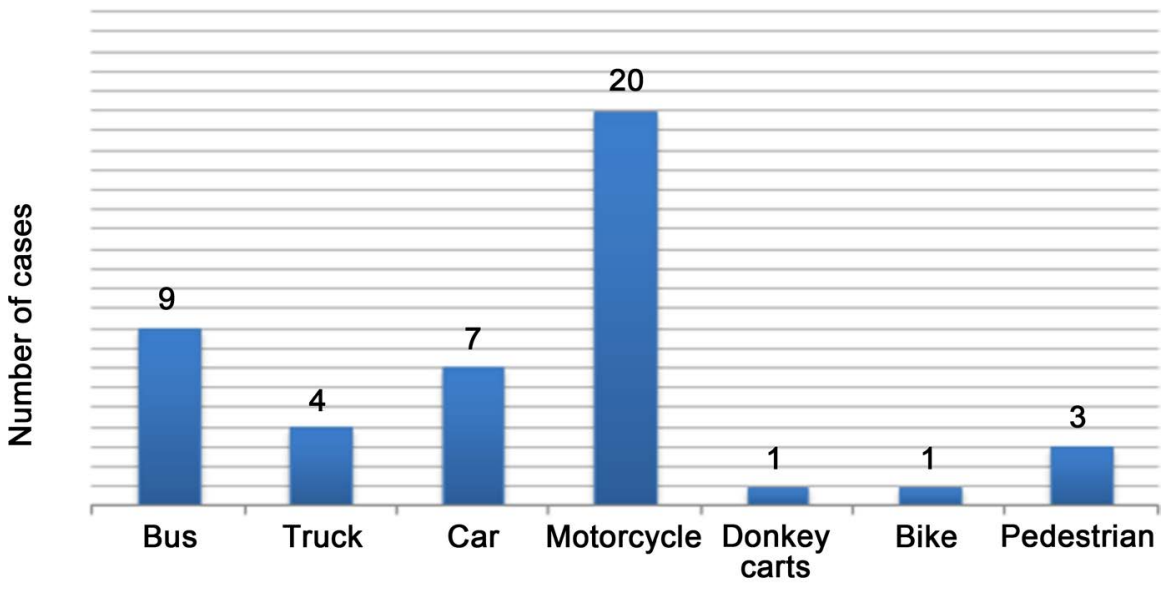

means of locomotio

Figure 3. Road Traffic Accidents distribution by accident type.

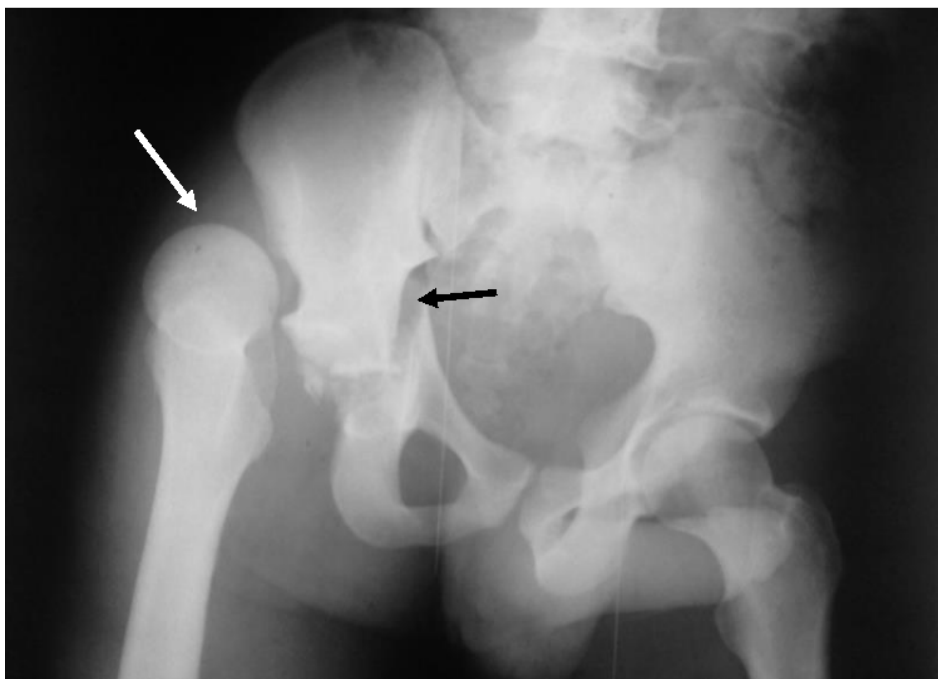

Figure 4. Pelvic radiograph (AP view) showed a right sus-acetabular irregular THD associated to an acetabular fracture.

Table 3. Classifications of THD cases.

\begin{tabular}{|c|c|c|c|}
\hline Type & & \multicolumn{2}{|c|}{ Cases (n) } \\
\hline Extra-pelvic & & & 45 \\
\hline Regular & & 43 & \\
\hline & Posterior & 33 & \\
\hline & Posterosuperior (Iliac) & 32 & \\
\hline & Posteroinferior (Ischiatic) & 1 & \\
\hline & Anterior & 10 & \\
\hline & Anterosuperior (Pubic) & 5 & \\
\hline & Anteroinferior (Thyroid) & 5 & \\
\hline Irregular (sus-acetabular) & & 2 & \\
\hline Intra-pelvic & & & 5 \\
\hline
\end{tabular}




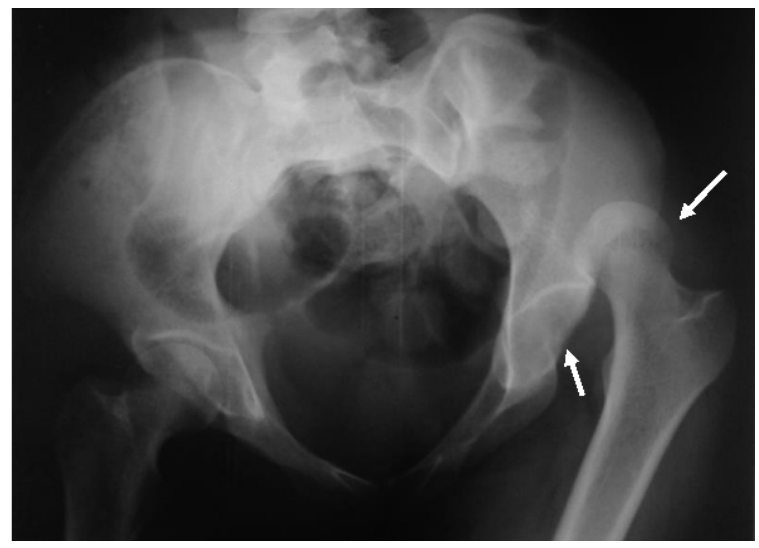

Figure 5. Pelvic radiograph (Inlet view) showed a left postero-superior (iliac) simple regular THD.

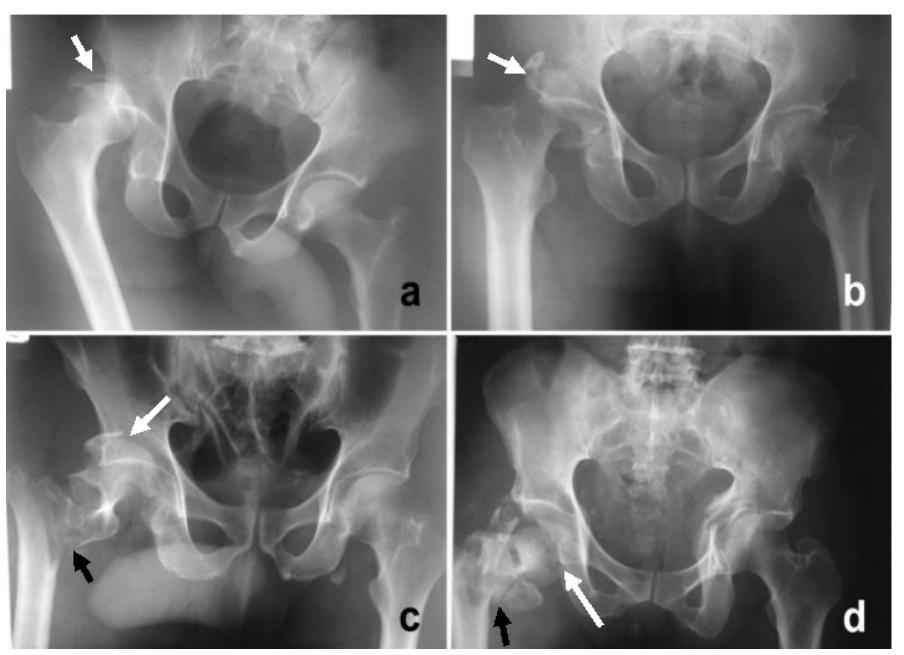

Figure 6. Pelvic radiographs (AP views) showed complicated posterior THD. (a) Right posterior THD with an associated acetabular posterior wall fracture. (b) Right posterior THD with associated femoral head and acetabular posterior wall fractures. (c) Right posterior THD with associated trochanteric and acetabular posterior wall fractures. (d) Right posterior THD with associated trochanteric and femoral head fractures and a left acetabular fracture.

\subsection{Treatment}

Closed reduction $(n=34)$, open reduction $(n=6)$ and Girdlestone procedure $(n=$ 1) were performed. Girdlestone procedure was performed on a patient with a neglected, 8-month-old obturator dislocation.

In five cases, the reduction was unstable. Eight patients refused the reduction and one patient died before reduction. Only half of THD cases were reduced in first six hours (Figure 7).

The delayed care and the distance to travel were statistically significant (corr. = $0.36, \mathrm{p}=0.018)$. The mean hospitalization time was 25 days (18.52 - 31.91). Twenty-three days' average trans-condylar traction was applied for 35 patients. No traction was applied was in the 15 other cases. The antithrombotic prophylaxis rate increased from zero in 2008 to nine tenth in 2013 and 2014. Twenty-two 
Table 4. Classifications of THD cases.

\begin{tabular}{|c|c|c|c|}
\hline Site & & & \\
\hline \multirow[t]{9}{*}{ Peri-articular associated fractures } & & & 48 \\
\hline & Acetabulum & 36 & \\
\hline & Posterior wall fracture & 23 & \\
\hline & Anterior wall fracture & 4 & \\
\hline & Both anterior and posterior walls & 8 & \\
\hline & Transverse fracture & 1 & \\
\hline & Femoral Head & 2 & \\
\hline & Femoral Neck & 3 & \\
\hline & Trochanteric region & 7 & \\
\hline \multirow[t]{16}{*}{ Other associated fractures } & & & 20 \\
\hline & Ipsilateral fractures & 12 & \\
\hline & Pelvic ring & 3 & \\
\hline & Femur & 3 & \\
\hline & Patella & 1 & \\
\hline & Tibia & 3 & \\
\hline & Ulna & 1 & \\
\hline & Costal bones & 1 & \\
\hline & Controlateral fractures & 8 & \\
\hline & Pelvic ring & 1 & \\
\hline & Femur & 1 & \\
\hline & Tibia & 1 & \\
\hline & Humerus & 1 & \\
\hline & Ulna & 2 & \\
\hline & Costal bones & 1 & \\
\hline & Tarsal bones & 1 & \\
\hline
\end{tabular}

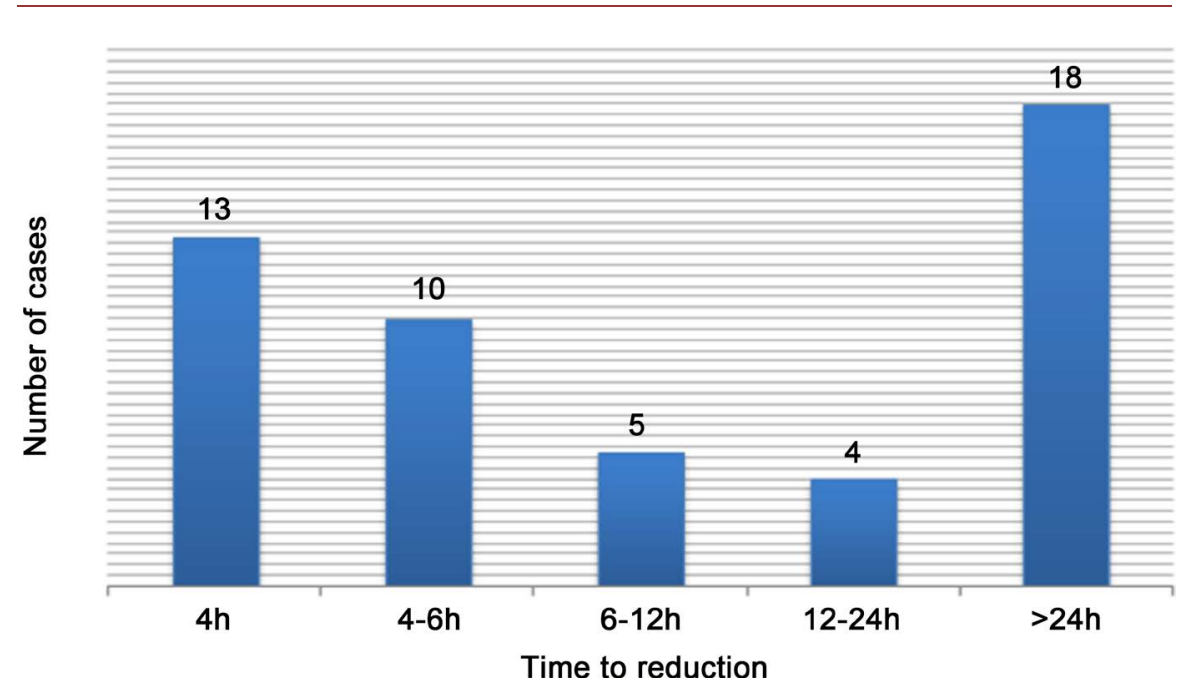

Figure 7. THD cases distribution by reduction time. 
patients had got physical rehabilitation. Weight bearing was authorized in the first week in simple THD $(\mathrm{n}=16)$ and after one to two months in complicated THD $(\mathrm{n}=34)$.

\subsection{Outcome}

Thirty-one patients were monitored, 17 others refused medical follow-up and left the hospital immediately or few days after their hip reduction. One patient with posterior fracture-dislocation of the hip associated with a contralateral diaphyseal femur fracture died after a massive post-reduction embolus.

The mean follow-up time for the followed patients was 16.23 months (11.36 21.08 IC95\%). The pregnant case of THD sustained an abortion after a retro placental hematoma. The functional evaluation by the Harris Hip Score (HHS) showed 21 good and excellent results. These results are better in the first year (Table 5). The HHS was better if a physical rehabilitation was performed $(r=$ $0.38, p=0.03)$. However, the HSS was not significantly improved in simple THD without any initial complication $(\mathrm{r}=-0.44, \mathrm{p}=0.0133)$. The functional outcome was good and excellent in all anterior THD except in one case who was received after one year. As short-term complications, we found ten osteoarthritis and three osteonecrosis. These complications and delayed reductions over four hours were statistically significant $(r=0.42, p=0.0322)$. The cases with a mean reduction time before seven hours showed no complication and the cases with a mean reduction time after 21 hours were all complicated. Tractions were not affected the functional outcome $(\mathrm{r}=-0.53, \mathrm{p}=0074)$ but were correlated to short-term complications $(r=0.45, p=0.02)$. Short-term complications were also linked to more than 14 days hospitalization time $(r=0.55, \mathrm{p}=0.0085)$, but not significantly linked to the associated fracture $(\mathrm{p}=0.066)$ that justified these longest hospitalizations.

\section{Discussion}

The coxo-femoral joint is a deep spheroid type joint that needs a strong femoral neck and a high energy trauma to dislocate [1] [4] [11]. Previously African series found around five cases of THD per year mainly men [8] [9]. This important rate is closed to our seven cases per year. It may be explained by the frequency of

Table 5. Harris Hip Score (HHS) grading by follow-up time.

\begin{tabular}{cccccc}
\hline Follow-up time & 3 months & $\mathbf{3}-\mathbf{6}$ months & $\mathbf{6}-\mathbf{1 2}$ months & $\mathbf{1 2}-\mathbf{1 8}$ months & Total \\
\hline HHS Grading & 1 & 0 & 0 & 2 & 3 \\
Poor & 0 & 0 & 0 & 1 & 1 \\
Fair & 0 & 3 & 5 & 1 & 9 \\
Good & 1 & 3 & 4 & 0 & 8 \\
Excellent & 2 & 6 & 9 & 4 & 21 \\
Total & & &
\end{tabular}


road traffic injuries in developing countries due to motor vehicles, roads conditions and pedestrians' habits. Men around the third decade of life are more exposed [5] [6] [8] [9].

The mean MOI of Hip dislocations are described as a car dashboard accident. Although the majority of our patients are drivers or passengers of two-wheelers, the concept of dashboard accident is still applicable, the collision is still making on a bent knee and a flexed hip. We called this mechanism of injury: "the motorcycle hip accident" (Figure 8).

Posterior regular THD is the more common dislocation [1]-[9]. Otherwise, our results showed an important rate of anterior regular THD (one fourth). The sitting position on motorcycles (hips open in flexion-abduction-external rotation) at the time of the trauma may led to more anterior dislocations. These dislocations are better prognosis [1] [12].

As associated peri-articular fractures, we found an important rate of acetabular fractures, mainly posterior wall fractures $(n=23)$. These fractures are common in posterior directed dislocations [2]. Our study presented an important rate of associated trochanteric fractures (Figure 6(c) and Figure 6(d)). It was also an exceptional association of a femoral head fracture, a trochanteric fracture with a posterior THD (Figure 6(d)). These associated trochanteric fractures might be explained by a two-time trauma: the first trauma produce the dislocation and the second the trochanteric fracture (Hit and fall from motorcycle). The computed tomography scan would be useful to diagnose more peri-articular fractures. Ipsilateral fractures, specially located on lower limb were more associated to posterior dislocations [4] [8].

In one half of cases, early reduction was performed as recommended [1] [2] [3]. Unfortunately, long distances to travel from rural lands and beliefs [13] lead to delayed reduction, refusals and deaths. Girdlestone procedure [14] in which the femoral neck and head are excised is a therapeutic solution [9] where a total hip arthroplasty is unavailable.

Some authors recommend a temporary traction after the reduction [15]. It was no consensus according to the use, the type and the duration of the traction. The use of traction did not affect our functional results but it might lead to

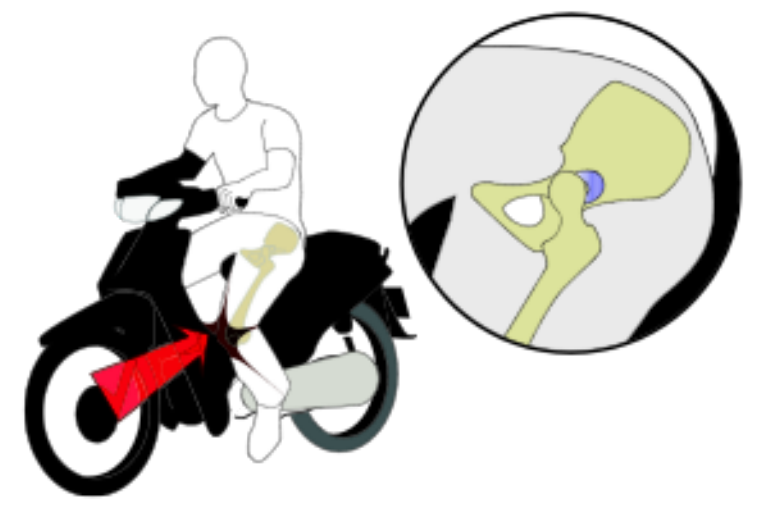

Figure 8. The "Motorcycle Hip Accident" type. 
short-term complications. We think that this might be explained the migration of osteochondral fragments and by the distraction effect on contused vessels.

Stuck and Vaughan stated that osteonecrosis might be reduced if weight bearing is delayed [16]. Other performed an earlier weight bearing [1]. The irregular checking and the number of loss of view patients made difficult for us the evaluation of weight bearing impact on functional outcome and short-term complications.

Our study showed better functional outcome in the first year in a THD reduced before four hours with an earlier rehabilitation program. Earlier rehabilitation keeps muscular strength and remodeling joint surfaces. Osteonecrosis of the femoral head and osteoarthritis of the hip joint are the main complications after a THD [1] [4]. Osteonecrosis appears first within two year in half percent of cases of delayed reduction over six hours [17]. Osteoarthritis appears much later [1]. Early osteonecrosis and osteoarthritis in the current study were improved by delayed reduction time over seven hours and long hospitalization time. Our lower rate of osteonecrosis might be increased if a nuclear magnetic resonance imaging (NMRI) was available. We found a high rate of early osteoarthritis (1/3 of THD). This was highly correlated to the use of traction and long hospitalizations time over 14 days. So, we recommend in case of THD, to reduce it before four hours, to avoid traction if possible, to perform earlier rehabilitation and to avoid over 14 days hospitalization time. Osteonecrosis must be checked after a year.

Our study has some limitations. Indeed, having no computed tomography and MRI, the morphological description of the osteo-articular lesions was certainly not optimal. Moreover, the small decline is also a limit when it is known that some complications (osteonecrosis and osteoarthritis) sometimes take place after two years of evolution. We believe that a study with longer follow-up and using MRI and CT for lesion diagnosis will yield even more relevant results.

\section{Conclusion}

The THD occurrences are important in our emergency department. They are characterized by the place of motorcycle accidents and by the delayed reduction due to hospital's locations and numbers and beliefs. The current study showed the advantage of an earlier reduction before four hours, an earlier physical rehabilitation and a short hospitalization time below 14 days and the disadvantage of tractions. However, functional outcome is good in the first year and complications such as osteonecrosis and osteoarthritis appear in the second year.

\section{References}

[1] Sanders, S., Tejwani, N. and Egol, K.A. (2010) Traumatic Hip Dislocation. Bulletin of the NYU Hospital for Joint Diseases, 68, 91-96.

[2] Thompson, V.P. and Epstein, H.C. (1951) Traumatic Dislocation of the Hip. The Journal of Bone \& Joint Surgery, 33, 746-792. 
https://doi.org/10.2106/00004623-195133030-00023

[3] Stewart, M.J. and Milford, L.W. (1954) Fracture-Dislocation of the Hip. The Journal of Bone \& Joint Surgery, 36, 315-342.

[4] Brav, E.A. (1962) Traumatic Dislocation of the Hip. The Journal of Bone \& Joint Surgery, 44, 1115-1134.

[5] Sahin, V., Karakaş, E.S., Aksu, S., Atlihan, D., Turk, C.Y. and Halici, M. (2003) Traumatic Dislocation and Fracture-Dislocation of the Hip: A Long-Term Follow-Up Study. The Journal of Trauma, 54, 520-529. https://doi.org/10.1097/01.TA.0000020394.32496.52

[6] Al-Bahlool, A.M., Bubshait, D.A. and Sadat-Ali, M. (2009) Outcome of Traumatic Hip Dislocation. Ulusal travma ve acil cerrahi dergisi = Turkish Journal of Trauma \& Emergency Surgery: TJTES, 15, 463-466.

[7] Bigelow, H.J.I. (1900) The Mechanism of Dislocations and Fracture of the Hip. Little, Brown, and Company.

[8] Allonge, T., Ogunlade, S. and Idowu, O. (2002) Traumatic Dislocation of the Hip Joint-Pattern and Management in a Tropical African Population. West African Journal of Medicine, 21, 288-290.

[9] Onyemaechi, N.O.C. and Eyichukwu, G.O. (2011) Traumatic Hip Dislocation at a Regional Trauma Centre in Nigeria. Nigerian Journal of Medicine, 20, 124-130.

[10] Harris, W.H. (1969) Traumatic Arthritis of the Hip after Dislocation and Acetabular Fractures: Treatment by Mold Arthroplasty. The Journal of Bone \& Joint Surgery, 51, 737-755. https://doi.org/10.2106/00004623-196951040-00012

[11] Obakponovwe, O., Morell, D., Ahmad, M., Nunn, T. and Giannoudis, P.V. (2011) Traumatic Hip Dislocation. Orthopaedics and Trauma, 25, 214-222. https://doi.org/10.1016/j.mporth.2011.04.006

[12] Dreinhöfer, K.E., Schwarzkopf, S.R., Haas, N.P. and Tscherne, H. (1994) Isolated Traumatic Dislocation of the Hip. Long-Term Results in 50 Patients. The Journal of Bone and Joint Surgery British Volume, 76, 6-12.

[13] Dakouré, P.W.H., Diallo, M., Traoré, A.-C.V., Gandéma, S., Barro, S.D., Traoré, I.A. and Zaré, C. (2015) Trauma Related to Falls from Trees Treated in a Specialized Trauma Centre in Burkina-Faso-One Hundred and Six Cases Treated in One Year. International Orthopaedics, 39, 2451-2456. https://doi.org/10.1007/s00264-015-2966-5

[14] Girdlestone, G.R. (1943) Acute Pyogenic Arthritis of the Hip: An Operation Giving Free Access and Effective Drainage. The Lancet, 241, 419-421. https://doi.org/10.1016/S0140-6736(00)41922-7

[15] Tornetta, P. and Mostafavi, H.R. (1997) Hip Dislocation: Current Treatment Regimens. Journal of the American Academy of Orthopaedic Surgeons, 5, 27-36. https://doi.org/10.5435/00124635-199701000-00004

[16] Stuck, W.G. and Vaughan, W.H. (1949) Prevention of Disability after Traumatic Dislocation of the Hip. The Southern Surgeon, 15, 659.

[17] Hougaard, K. and Thomsen, P.B. (1986) Traumatic Posterior Dislocation of the Hip-Prognostic Factors Influencing the Incidence of Avascular Necrosis of the Femoral Head. Archives of Orthopaedic and Traumatic Surgery, 106, 32-35. https://doi.org/10.1007/BF00435649 